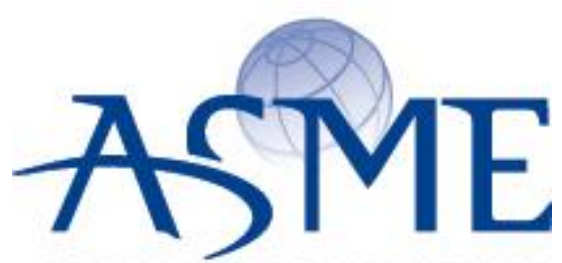

SETTING THE STANDARD

\section{American Society of Mechanical Engineers}

ASME Accepted Manuscript Repository

Institutional Repository Cover Sheet

Cranfield Collection of E-Research - CERES

First

Last

ASME Paper Title: Analysis of a high pressure ratio intercooled direct Brayton helium gas turbine cycle for

Generation IV reactor power plants

Authors: $\quad$ A. Gad-Briggs, P. Pilidis \& T. Nikolaidis

ASME Journal Title: Journal of Nuclear Engineering and Radiation Science

Volume/Issue __Vol. 3, Iss. 1

Date of Publication (VOR* Online)

20.12.2016

ASME Digital Collection URL: http://nuclearengineering.asmedigitalcollection.asme.org/article.aspx?articleid=2546052

DOI:

*VOR (version of record) 


\title{
Analyses of a High Pressure Ratio Intercooled Direct Brayton Helium Gas Turbine Cycle for Generation IV Reactor Power Plants
}

A Gad-Briggs
a.a.gadbriggs@cranfield.ac.uk

Gas Turbine Engineering Group,

Cranfield University, Cranfield, Bedfordshire, MK43 0AL U.K.

\section{P Pilidis}

p.pilidis@cranfield.ac.uk
T Nikolaidis

t.nikolaidis@cranfield.ac.uk

\begin{abstract}
The Intercooled Cycle (IC) as an alternative to the Simple Cycle Recuperated (SCR) and Intercooled Cycle Recuperated (ICR), is yet to be fully analysed for the purpose of assessing its viability for utilisation within Generation IV Nuclear Power Plants (NPPs). Although the benefits are not explicitly obvious, it offers the advantage of a very high Overall Pressure Ratio (OPR) in the absence of a recuperator. Thus, the main objective of this study is to analyse for various pressure ratio configurations, the effects of varying pressure ratio including sensitivity analyses of component efficiencies, ambient temperature, component losses and pressure losses on cycle efficiency and specific work of the IC, including comparison with the SCR and ICR. Results of comparison between the IC and the SCR and ICR, derived cycle efficiencies greater than the IC by $\sim 4 \%$ (SCR) and $\sim 6 \%$ (ICR) respectively. However, the pressure losses for IC are lower when compared to SCR and ICR. Nonetheless, heat from the turbine exit temperature of the IC can be used in a processing plant including the possibility of higher Turbine Entry Temperatures (TET) to significantly increase the cycle efficiency in a bid to justify the business case. The analyses intend to bring to attention an alternative to current cycle configurations for the Gas Cooled Fast Reactors (GFRs) and Very High Temperature Reactors (VHTRs), where helium is the coolant. The findings are summarised by evaluating the chosen pressure ratio configurations against critical parameters and detailed comparison with the SCR and ICR.
\end{abstract}

Keywords: Gen IV, Efficiency, Specific Work, Cycle, Nuclear Power Plants, Performance, Split, Intercooled.

\begin{tabular}{|c|c|}
\hline \multicolumn{2}{|c|}{ Nomenclature } \\
\hline \multicolumn{2}{|c|}{ Notations } \\
\hline$A$ & Area $\left(\mathrm{m}^{2}\right)$ \\
\hline$C p$ & Spec. Heat of Gas at Constant Pressure $(\mathrm{J} / \mathrm{kg} \mathrm{K})$ \\
\hline$C W$ & Compressor Work (W) \\
\hline$m$ & Mass Flow Rate (kg/s) \\
\hline$P$ & Pressure $(\mathrm{Pa})$ \\
\hline$P R$ & Pressure Ratio \\
\hline$Q$ & Reactor Thermal Heat Input \\
\hline$q$ & Heat Flux $\left(\mathrm{W} / \mathrm{m}^{2}\right)$ \\
\hline$S W$ & Specific Work/Power Output (W/Kg/s) \\
\hline$T$ & Temperature $\left(\mathrm{K}\right.$ or $\left.^{\circ} \mathrm{C}\right)$ \\
\hline$T R$ & Temperature Ratio ( $\mathrm{T}_{4} / \mathrm{T}_{1}$; expressed in Kelvin) \\
\hline$T W$ & Turbine Work (W) \\
\hline$W$ & Work (W) \\
\hline$U W$ & Useful Work (W) \\
\hline
\end{tabular}

\section{Greek Symbols}

$\gamma \quad$ Ratio of Specific Heats

$\Delta \quad$ Delta, Difference

$\varepsilon \quad$ Effectiveness (Heat Exchanger)

$\eta \quad$ Thermal Efficiency

\section{Subscripts}

$\begin{array}{ll}c & \text { Compressor } \\ c_{\text {in }} & \text { Compressor Inlet } \\ c_{\text {out }} & \text { Compressor Outlet } \\ e & \text { Power for Electrical Conversion } \\ h e & \text { Helium } \\ i s_{c} & \text { Isentropic (Compressor) } \\ i s_{t} & \text { Isentropic (Turbine) } \\ M H R & \text { Reactor (Heat Source) } \\ M H R_{\text {in }} & \text { Reactor (Heat Source) Inlet } \\ M H R_{\text {loss }} \text { Reactor (Heat Source) Pressure Losses } \\ M H R_{\text {out }} \text { Reactor (Heat Source) Outlet } \\ p c_{\text {in }} & \text { Precooler Inlet (also applicable to intercooler) } \\ p c_{\text {loss }} & \text { Precooler Pressure Losses (same as above) } \\ p c_{\text {out }} & \text { Precooler Outlet (same as above) } \\ t h & \text { Thermal Power } \\ t & \text { Turbine } \\ t_{\text {out }} & \text { Turbine Outlet } \\ t_{\text {in }} & \text { Turbine Inlet }\end{array}$

$\begin{array}{ll}\text { Abbreviations } \\ \text { CH } & \text { Precooler (Figure 1) } \\ \text { COT } & \text { Core Outlet Temperature } \\ \text { DP } & \text { Design Point } \\ \text { G } & \text { Generator }\end{array}$

GEN IV Generation Four 


$\begin{array}{ll}\text { GFR } & \text { Gas-Cooled Fast Reactor } \\ \text { GIF } & \text { Generation IV International Forum } \\ \text { HPC } & \text { High Power Compressor } \\ \text { IC } & \text { Intercooled Cycle; Intercooler (Figure 1) } \\ \text { ICR } & \text { Intercooled Cycle Recuperated } \\ \text { LPC } & \text { Low Power Compressor } \\ \text { MHR } & \text { Modular Helium Reactor } \\ \text { NPP } & \text { Nuclear Power Plant } \\ \text { NTU } & \text { Number of Transfer Units } \\ \text { OPR } & \text { Overall Pressure Ratio } \\ \text { PC } & \text { Precooler } \\ \text { R } & \text { Reactor (Figure 1) } \\ \text { RPV } & \text { Reactor Pressure Vessel } \\ \text { SCR } & \text { Simple Cycle Recuperated } \\ \text { T } & \text { Turbine } \\ \text { TET } & \text { Turbine Entry Temperature } \\ \text { VHTR } & \text { Very High Temperature Reactor }\end{array}$

\section{Introduction}

Simplification of the cycle and plant design are key to Generation IV framework to ensure improved life cycle and cost of energy production [1]. In doing so, it is expected that the cycle efficiency will be improved in comparison to the incumbent designs [2]. The intercooled cycle has gone through technological advancements, with gas turbines such as the General Electric LMS100 achieving 46\% efficiency with air as the working fluid, prompting studies as documented in [3]. Incorporating this cycle configuration without a recuperator has not been fully explored, due to the perceived economics of a nuclear gas turbine cycle without a recuperator to capture the exhaust heat and transfer back into cycle. Nonetheless, prior to assessing the economics, its performance potential needs to be analysed and understood in order to enable evaluation against the simple and intercooled recuperated cycles. The objective is to conduct a thermodynamic study using a performance simulation tool to analyse the Intercooled Cycle (IC) in a closed Brayton direct configuration using helium as the working fluid.

\section{Generation IV (Gen IV) Systems}

The Gas-Cooled Fast Reactor System (GFR) and Very-HighTemperature Reactor System (VHTR) are applicable to this study. The GFR has helium as the coolant and possesses a high temperature capability and fast spectrum nuclear core. Core Outlet Temperature (COT) is between $850-950^{\circ} \mathrm{C}$, which is enabled by an efficient direct thermodynamic Brayton cycle. Having helium as the working fluid means single phase cooling with a chemically inert and stable gas and neutronic transparency. Just as with the GFR, the VHTR is also a high temperature thermal reactor that is also cooled by helium in gaseous phase, with graphite providing the moderation in the solid state. The core delivers a COT of $750-1000^{\circ} \mathrm{C}$, which means significant rises in cycle efficiency with helium not altering its gas properties due to increased temperature, and graphite possessing the necessary mechanical properties to provide moderation. The Gen IV Forum (GIF) states that several demonstration projects are in the early planning phase with the aim of testing basic concepts and demonstrating performance. The planned demonstrator reactors are described and discussed in [1].

\section{Intercooled Brayton Cycle (IC)}

The IC requires a Low Pressure Compressor (LPC), a High Pressure Compressor (HPC) and a turbine as part of the turbomachinery. Overall compressor work is lower than turbine work, thus useful work can be used to drive the generator load but due to component inefficiencies, the compression and expansion phases are not isentropic. As a result, heating and cooling of the cycle is not achieved at constant pressure, hence losses are observed in the cycle. The losses translate into more work input required for the overall compression process due to increase in temperature, resulting in a higher exit temperature. The heat addition into the cycle is not isobaric, which reduces total gas exit pressure, thus total power extraction possible is reduced due to reduced gas exit pressure and reduced component efficiencies. The turbine exit heat is typically hotter than expected, which makes overall compression inlet temperature hotter than ideal. The IC cycle improves the specific and useful work when compared to cycles, where no intercooled compression is utilised. This can be demonstrated if the HPC inlet is intercooled to the same inlet temperature as the LPC inlet [4].

A precooler, in addition to the aforementioned turbomachinery components would be part of the cycle and would be utilised in a typical NPP. The addition of the precooler, ensures the working fluid can be cooled by a cooling medium (usually seawater) at the LPC entry to achieve the necessary cycle inlet temperature. This reduces the LPC work for a given temperature and pressure increase at exit prior to entry into the HPC. Increase in pressure at the HPC entry is desired, but a temperature rise at the HPC inlet would require more work to achieve the temperature and pressure rise at a higher than observed pressure ratio, when compared to the LPC. This translates into an additional reactor thermal power increase beyond what is required and results in cycle efficiency penalties. Due to the reactor thermal power being fixed for a given COT, the precooler alone will not yield the specific work required for the NPP, which devalues the economics of the plant.

An intercooler is introduced downstream of the LPC, which in principle cools the working fluid down to the cycle inlet temperature as a mitigation to reduce the HPC compressor work for a given pressure ratio, with negligible reduction in already achieved pressure rise at that stage. Without any heat exchange in the cycle, it is demonstrated in this study that an even pressure ratio split between the two compressors (determined per compressor as the square root of the OPR), will not yield the maximum cycle efficiency. It is also demonstrated that the Overall Pressure Ratio (OPR) of the cycle will not be low. The OPR will need to be at its highest and will need to have 
an optimum split ratio between the LPC and HPC in order to achieve the maximum cycle efficiency, taking into account component losses.

Thermodynamic consequences of parameters as a result of changing from air to helium for nuclear gas turbines have been extensively covered in [5]. Although the study, which is also documented in [6] and [7] focuses on off-design, control and transient operational modes of a helium gas turbine, it provides good bases for future off-design analyses, which will be applicable to IC, SCR and ICR configurations.

\section{Modelling of Nuclear Power Plants and Performance Simulation Tool}

Figure 1 illustrates a typical schematic of an Intercooled Cycle, which can be adopted for NPPs. Table 1 provides key design point values for modelling using the performance simulation tool.

The performance of a typical helium cooled NPP utilising IC under the conditions in table 1 , were modelled and simulated using a FORTRAN based tool developed as part of this study. Values for the component efficiencies and pressure losses are comparable to typical values of other Brayton nuclear cycles, utilising helium as the working fluid, for the given TET, and are considered satisfactory for this study. The optimum OPR to provide the optimum core inlet temperature into the reactor to derive the best cycle efficiency was unknown. It was calculated for a wide range of OPRs (e.g. 1-50) with varied compression split ratios between the LPC and HPC for each OPR. The challenges of this task include ensuring stability in the calculation; allowing storage and transfer capability for the excessive amount of data to be produced and a post processing method that would ensure selection of optimum results. This was made possible due to specific functions built into the code algorithm within FORTRAN. The mathematical equations implemented within the code environment to calculate the station and cycle parameters are described in the proceeding sections for steady state design point calculations against each component.

\section{$\underline{L P C} \& H P C$}

Prerequisite parameters for performance design considerations of both compressors include the compressor pressure ratio, compressor inlet conditions (temperature, pressure and mass flow rate), component efficiency and the working fluid gas properties ( $C p$ and $\gamma$ ). The compressor outlet pressure $(\mathrm{Pa})$ is:

$$
P_{c_{\text {out }}}=P_{c_{\text {in }}} \cdot P R_{c}
$$

The isentropic efficiency of the compressor is $\frac{T_{\text {rise }_{\text {ideal }}}}{T_{\text {rise }_{\text {actual }}}}$ and is also indicative of the specific work input or total temperature increase. Thus, the temperature $\left({ }^{\circ} \mathrm{C}\right)$ at the exit can be derived from the inlet temperature, pressure ratio, isentropic efficiency and ratio of specific heats:

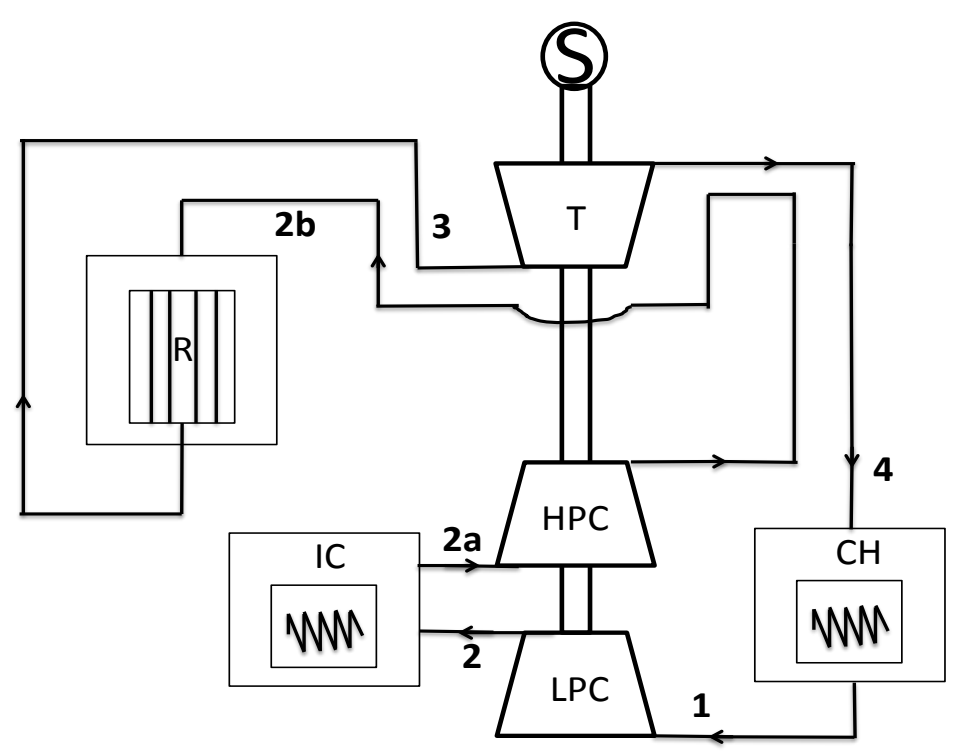

Figure 1 - Typical Intercooled Cycle

Table 1 - IC Input Values for Modelling

\begin{tabular}{|l|l|l|}
\hline \multicolumn{1}{|c|}{ Inputs } & Values & Units \\
\hline Inlet Temp. & 28 & ${ }^{\circ} \mathrm{C}$ \\
\hline TET (Core outlet temp) & 950.0 & ${ }^{\circ} \mathrm{C}$ \\
\hline Inlet Pressure & 3.21 & $\mathrm{MPa}$ \\
\hline Mass flow rate at inlet & 410.4 & $\mathrm{~kg} / \mathrm{s}$ \\
\hline *LPC Efficiency (Isentropic) & 90 & $\%$ \\
\hline *HPC Efficiency (Isentropic) & 90 & $\%$ \\
\hline *Turbine Efficiency (Isentropic) & 94.5 & $\%$ \\
\hline Pressure Loss (Precooler) & 2.5 & $\%$ \\
\hline Pressure Loss (Intercooler) & 2.5 & $\%$ \\
\hline Pressure Loss (Reactor) & 2 & $\%$ \\
\hline Turbine Cooling flow (\% massflow rate) & 1 & $\%$ \\
\hline Reactor Cooling flow (\% massflow rate) & 0.25 & $\%$ \\
\hline
\end{tabular}

*Compressor and Turbine efficiencies are based on technological improvements in [8].

$$
T_{c_{\text {out }}}=T_{c_{\text {in }}} \cdot\left[1+\frac{\left(\frac{{ }_{c_{\text {out }}}}{P_{c_{\text {in }}}}\right)^{\frac{\gamma-1}{\gamma}}-1}{\eta_{\text {is }_{c}}}\right]
$$

The mass flow rate $(\mathrm{kg} / \mathrm{s})$ at inlet is equal to the mass flow rate at outlet as there are no compositional changes:

$$
m_{c_{\text {out }}}=m_{c_{\text {in }}}
$$


The compressor work (W) is the product of the mass flow rate, specific heat at constant pressure and the temperature delta:

$$
\begin{aligned}
& C W=m_{c} \cdot C p_{h e} \cdot\left(\Delta T_{c}\right) \\
& \text { whereby } \Delta T_{c}=T_{c_{\text {out }}}-T_{c_{\text {in }}}
\end{aligned}
$$

Bypass splitters are incorporated within the performance simulation tool, to allow for compressed coolant to be bled from the LPC for reactor cooling, and from the HPC for turbine cooling. The reactor cooling demands negligible cooling flow at moderate pressures because it is assumed that the opposing pressures within the reactor outer wall and pressure vessel inner wall will not restrict cooling flow for the reactor. The HPC must be used to deliver coolant for turbine cooling because the coolant must be at a higher pressure than that observed in the turbine, in order to be delivered effectively.

\section{Turbine}

Prerequisite parameters of the turbine include the turbine inlet conditions (temperature, pressure and mass flow rate), the pressure at outlet, component efficiency and the working fluid gas properties ( $C p$ and $\gamma$ ).

The temperature $\left({ }^{\circ} \mathrm{C}\right)$ at the outlet is derived from the following expression:

$$
T_{t_{\text {out }}}=T_{t_{\text {in }}} \cdot\left\{1-\eta_{\text {ist }_{t}}\left[1-\left(\frac{P_{t_{\text {out }}}}{P_{t_{\text {in }}}}\right)^{\frac{\gamma-1}{\gamma}}\right]\right\}
$$

As with the compressor, eqs (3) and (4) also apply to the turbine for mass flow rate $(\mathrm{kg} / \mathrm{s})$ conditions and turbine work (W) but:

$$
\Delta T_{t}=T_{t_{\text {in }}}-T_{t_{\text {out }}}
$$

A mixer is incorporated within the performance simulation tool to allow for the coolant to mix with the hot gas to simulate turbine cooling.

\section{Precooler and Intercooler}

Prerequisite parameters for the precooler and intercooler takes into account that the precooler is upstream of the LPC and the intercooler is downstream of the LPC and upstream of the HPC, thus compressor inlet temperature and pressure are of importance including the pressure losses. The conditions for the precooler are as follows:

$$
\begin{aligned}
& T_{p c_{\text {out }}}=T_{c_{\text {in }}} \\
& P_{p c_{\text {in }}}=P_{p c_{\text {out }}} \cdot\left(1+\Delta P_{p c_{\text {loss }}}\right) \\
& m_{p c_{\text {out }}}=m_{p c_{\text {in }}}
\end{aligned}
$$

With regard to the intercooler, eqs (8), (9) and (10) apply but are differentiated within the code to ensure exclusivity to the respective components.

\section{Modular Helium Reactor}

As a heat source with inevitable pressure losses, the prerequisite are the thermal heat input from burning the fuel and the known reactor design pressure losses.

The heat source does not introduce any compositional changes thus mass flow rate $(\mathrm{kg} / \mathrm{s})$ is:

$$
m_{M H R_{\text {out }}}=m_{M H R_{\text {in }}}
$$

Pressure taking into account losses (\%):

$$
P_{\text {MHR out }}=P_{\text {MHRin }} \cdot\left(1-\Delta P_{\text {MHR loss }}\right)
$$

and the thermal heat input $(\mathrm{W} t)$ is:

$$
Q_{M H R}=m_{M H R_{i n}} \cdot C p_{h e} \cdot\left(\Delta T_{M H R}\right)
$$

whereby $\Delta T_{M H R}=T_{M H R_{\text {out }}}-T_{M H R_{\text {in }}}$

A mixer is incorporated within the code to allow for the coolant to be mixed with the heated fluid upstream of the reactor, in order to simulate reactor vessel cooling.

\section{Cycle Calculations}

The useful work, specific work and thermal efficiency output values are of interests after executing each set of station parametric calculations. The useful work (We) that is the work available for driving the load is:

$$
U W=T W-C W
$$

whereby $C W$ is the summation of both compressors' work requirement to be delivered by the turbine. The specific work or capacity of the plant $(\mathrm{W} / \mathrm{kg} / \mathrm{s})$ is:

$$
S W=U W / W
$$

and the thermal efficiency (\%) of the cycle is:

$$
\eta_{t h}=U W / Q_{M H R}
$$

Figure 2 denotes the typical structure of the performance simulation code for IC. The calculation algorithms are tailored to the conditions driven by the requirements of the cycle. The tool was used determine optimum OPRs, reactor core inlet temperatures and maximum cycle efficiency for 5 different OPR configurations. This was achieved by assessing a wide range of OPRs and various PR split ratios for each OPR. 
The calculation input values from table 1 such as TET were unchanged.

\section{Results and Discussion}

\section{Deriving Cycle Configurations for Analysis}

Table 2 lists the optimal OPR configurations for 5 options that were calculated; table 3 provides the mass flow rates, pressures and temperatures for each option in line with the cycle schematic in Figure 1; table 4 lists the output results of each option.

The chosen OPR configurations and splits first of all, enables demonstration of the performance of a 50:50 split in comparison to the uneven configuration, where the HPC has a much higher PR than the LPC. Furthermore, it can be demonstrated that slight variations of the PR in both the LPC and HPC of the uneven configuration can yield comparable thermal efficiencies. However, when sensitivity analyses of critical parameters are taken into account, distinguishable differences are noted as explained later in this paper.

With reference to table 3 , the IC has 2 additional stages denoted as $2 \mathrm{a}$ and $2 \mathrm{~b}$ that enables the coolant to be cooled to the same inlet temperature as observed

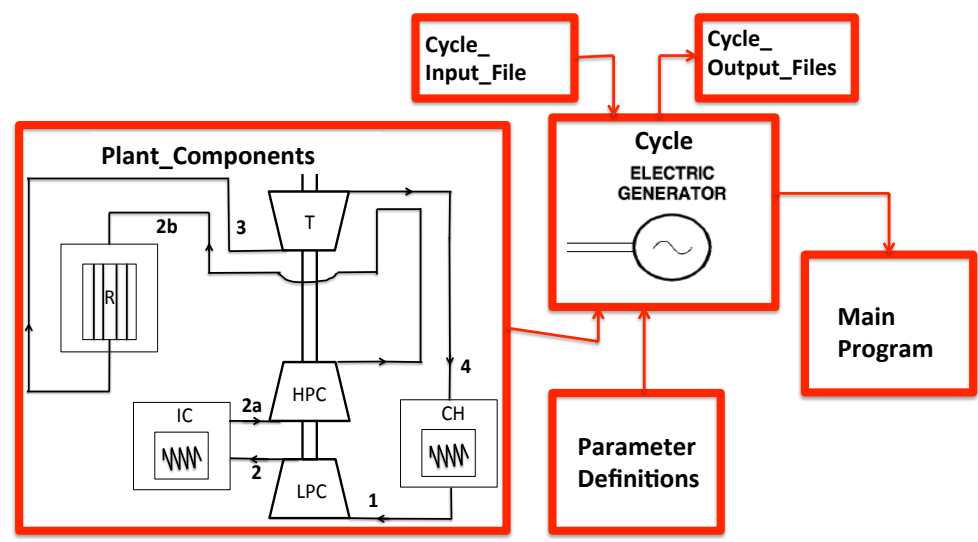

Figure 2 - Performance Simulation Tool Structure for IC at the first compressor and retaining the higher exit pressure, although with some negligible pressure losses observed in most cases, prior to entering into a second compressor. The pressure after LPC compression shows that the pressure rise is in line with the pressure ratio apportioned to each configuration in table 2. The same statement holds true for the temperature rise due to the temperature ratio and pressure ratio relationship. The level of pressure and temperature rise experienced in the HPC is also dependent on HPC pressure ratio, taking into account component losses. The compressor delivery temperature to the reactor, determines the level of thermal power input required to raise the TET to $950^{\circ} \mathrm{C}$. The energy balance of the cycle is determined after expansion and power extraction to drive the load; It can be observed that the exhaust heat is higher for option 1 and 5 . The exhaust heat has to be cooled down by the precooler to ensure an appropriate cycle entry temperature; alternatively, it can be used for secondary processes.

As noted, the biggest variation observed is the temperature parameter. The effect is evident in cycle results in table 4 . Table 4 shows that the largest compressor work observed was option 4 followed by option 2, although option 2 has third largest OPR in comparison to option 4 and 3. This is because it has the largest HPC PR out of all options. The turbine work and useful work follow a similar pattern as the compressor work, although it is noted that option 1 has the largest useful work (19\% more). The main reason for this is attributed to the reactor heat input (28\% more) into the cycle, required to raise the TET to $950^{\circ} \mathrm{C}$. This extra heat is only possible if more fuel is burnt. This means the capacity of the plant or the specific work has to be increased by approximately $19 \%$ to accommodate additional fuel and corroborates well with the increase in useful work observed. Regardless of the increases in useful work observed, the cycle efficiency in option 1 is the lowest when compared to other options. Option 2 provides the highest efficiency rating, which is marginally better than options 3,4 and 5 .

Table 2 - Overall Pressure Ratio Configurations (Optimal)

\begin{tabular}{|c|c|c|c|c|c|c|c|c|c|c|c|c|c|c|}
\hline \multicolumn{3}{|c|}{ Opt1 (50:50 split; V OPR) } & \multicolumn{3}{|c|}{ Opt2 } & \multicolumn{3}{|c|}{ Opt3 } & \multicolumn{3}{|c|}{ Opt4 } & \multicolumn{3}{|c|}{ Opt5 } \\
\hline LPC PR & HPC PR & OPR & LPC PR & HPC PR & OPR & LPC PR & HPC PR & OPR & LPC PR & HPC PR & OPR & LPC PR & HPC PR & OPR \\
\hline 3.4 & 3.4 & 11.8 & 1.7 & 8.1 & 13.8 & 1.8 & 7.8 & 14.04 & 2 & 7.4 & 14.8 & 1.4 & 8.8 & 12.32 \\
\hline
\end{tabular}

Table 3 - Station Output Values

\begin{tabular}{|c|c|c|c|c|c|c|c|c|c|c|c|c|c|c|c|c|}
\hline & & \multicolumn{5}{|c|}{ Massflow } & \multicolumn{5}{|c|}{ Pressure } & \multicolumn{5}{|c|}{ Temperature } \\
\hline & & & & {$[\mathrm{kg} / \mathrm{s}]$} & & & & & [MPa] & & & & & {$\left[{ }^{\circ} \mathrm{C}\right]$} & & \\
\hline & & Opt 1 & Opt 2 & Opt 3 & Opt 4 & Opt 5 & Opt 1 & Opt 2 & Opt 3 & Opt 4 & Opt 5 & Opt 1 & Opt 2 & Opt 3 & Opt 4 & Opt 5 \\
\hline St & 1 & 410.4 & 410.4 & 410.4 & 410.4 & 410.4 & 3.21 & 3.21 & 3.21 & 3.21 & 3.21 & 28 & 28 & 28 & 28 & 28 \\
\hline St & 2 & 406.3 & 409.37 & 409.37 & 409.37 & 409.37 & 11.03 & 5.46 & 5.78 & 6.42 & 4.49 & 241 & 107 & 116 & 135 & 76 \\
\hline St & $2 a$ & 406.3 & 409.37 & 409.37 & 409.37 & 409.37 & 11.03 & 5.32 & 5.63 & 6.26 & 4.38 & 28 & 28 & 28 & 28 & 28 \\
\hline St & $2 b$ & 406.3 & 406.31 & 406.31 & 406.31 & 406.31 & 37.88 & 43 & 42.72 & 46.22 & 38.47 & 241 & 464 & 444 & 436 & 489 \\
\hline St & 3 & 406.3 & 406.31 & 406.31 & 406.31 & 406.31 & 36.93 & 42.14 & 41.87 & 45.3 & 37.7 & 950 & 950 & 950 & 950 & 950 \\
\hline St & 4 & 410.4 & 410.4 & 410.4 & 410.4 & 410.4 & 3.29 & 3.29 & 3.29 & 3.29 & 3.29 & 233 & 210 & 211 & 198 & 229 \\
\hline
\end{tabular}


Table 4 - Cycle Results

\begin{tabular}{|c|c|c|c|c|c|c|c|c|c|c|c|c|c|c|}
\hline \multicolumn{5}{|c|}{ CW } & \multicolumn{5}{|c|}{ TW } & \multicolumn{5}{|c|}{ UW } \\
\hline \multicolumn{5}{|c|}{ [MW] } & \multicolumn{5}{|c|}{ [MW] } & \multicolumn{5}{|c|}{ [MW] } \\
\hline Opt 1 & Opt 2 & Opt 3 & Opt 4 & Opt 5 & Opt 1 & Opt 2 & Opt 3 & Opt 4 & Opt 5 & Opt 1 & Opt 2 & Opt 3 & Opt 4 & Opt 5 \\
\hline 903.15 & 1096.12 & 1075.30 & 1097.11 & 1085.5 & 1513.64 & 1567.12 & 1564.55 & 1591.94 & 1527.16 & 610.49 & 471.00 & 489.25 & 494.83 & 441.62 \\
\hline \multicolumn{5}{|c|}{ SW } & \multirow{2}{*}{\multicolumn{5}{|c|}{$\begin{array}{c}\text { Heat Input } \\
{[\mathrm{MWt}]}\end{array}$}} & \multirow{2}{*}{\multicolumn{5}{|c|}{$\frac{n}{[\%]}$}} \\
\hline \multicolumn{5}{|c|}{$[\mathrm{MW} / \mathrm{kg} / \mathrm{s}]$} & & & & & & & & & & \\
\hline Opt 1 & Opt 2 & Opt 3 & Opt 4 & Opt 5 & Opt 1 & Opt 2 & Opt 3 & Opt 4 & Opt 5 & Opt 1 & Opt 2 & Opt 3 & Opt 4 & Opt 5 \\
\hline 1.49 & 1.15 & 1.19 & 1.21 & 1.08 & 1496.4 & 1026.69 & 1067.4 & 1084 & 972.28 & 40.80 & 45.88 & 45.84 & 45.65 & 45.42 \\
\hline
\end{tabular}

Effects of Varying Pressure Ratio on Thermal Efficiency and Specific Work

Figure 3 shows the effects of varying OPR on cycle efficiency and specific work for a TET of $950^{\circ} \mathrm{C}$. The curves represent all 5 PR configurations. As evident, option 1 efficiency curve for the range of OPRs calculated (8 - 18), provides a different trend in comparison to other options, which are comparable. It is worth re-iterating that the only parameter variation is the PR apportionment for the LPC and HPC. With the exception of option 5, which deteriorates at a faster rate, options 2, $3 \& 4$ are comparable in values; option 2 are 3 are almost identical, hence why a single curve is used to represent them.

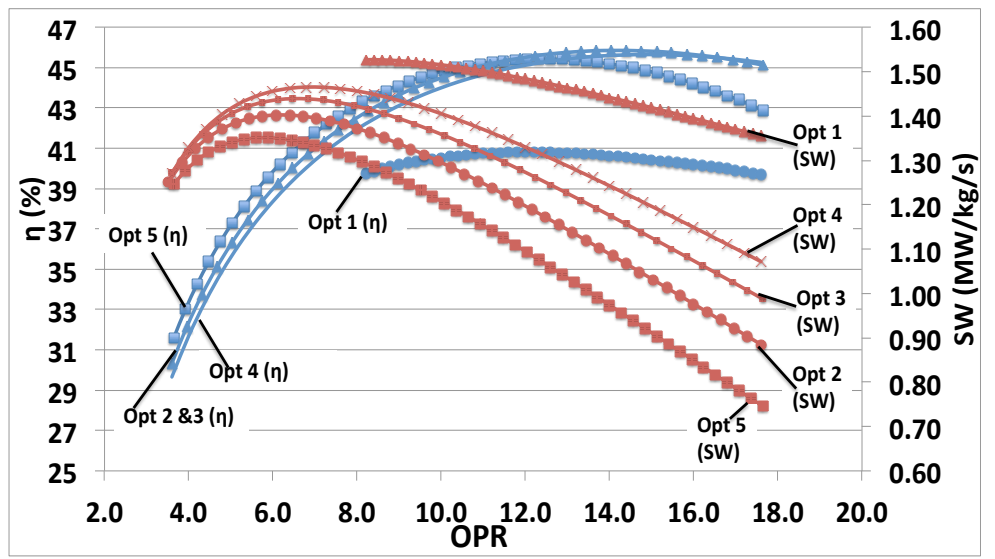

Figure 3 - Effect of OPR on Efficiency and Specific Work

With regard to efficiency, increases in OPRs led to increases to efficiency but beyond the optimal OPR, deterioration in efficiency is observed. Option 5 is provided in this analysis to demonstrate the importance of optimum OPR split between the LPC and HPC. Option 5 has an OPR of 12.32, which is comparable to option 1 (11.88), with the same values as per table 1, used in the calculations. Beyond these OPRs, deterioration in efficiency is experienced. Option 5 OPR is $4.22 \%$ higher that option 1 . In addition, the delta in efficiency between both options is $4.62 \%$. This seems to suggest that there is a correlation between increase in OPR for a cycle and increase in efficiency, when compared to another cycle, with the same configuration. However, this does not hold true when the efficiencies and OPRs are compared for options 2, 3 and 4.
Furthermore, the efficiency delta between options 1 and 2 is $\sim 5 \%$; the OPR delta is $\sim 14 \%$ so no linear correlation exist as previously implied. Nonetheless it has been demonstrated using option 5 for comparison, that there are efficiency penalties, when an even PR split is adopted for the IC cycle.

With regard to specific work, it is evident for all options that the associate efficiencies yield lower that observed specific work. There is a $27.5 \%$ increase in SW for option 1, when compared to option 5 , which points to additional plant capacity (increase in fuel burnt due to increase in thermal heat), for a comparable OPR. There is negligible difference in SW between OPRs for option 2, 3 and 4. Cycle economics do not prioritise the amount of power a plant can deliver, which will require significant scaling up of components, and incorporating smaller fuel schedules or increasing the size of the reactor to accommodate more fuel to increase output, at the expense of thermal efficiency. Closing the fuel cycle or lessening the refuelling schedule is key to achieving the sustainability goal as part of the Generation IV objectives thus a change in refuelling demand will not be preferred. Scaling up in plant size will increase the capital costs and subsequent maintenance costs, which is less favourable and not justifiable when it compromises thermal efficiency. Option 1 was no longer considered in further analysis during this study due to its poor efficiency; option 5 was also not considered for further analysis because the purpose for its inclusion was to demonstrate the performance of option 1 .

\section{Sensitivity Analysis - Component Efficiencies}

Figures 4, 5 and 6 show component sensitivities for the LPC, HPC and turbine respectively and their effect on the cycle efficiency. For each component, all 3 OPR configurations of interest are shown.

With regard to the LPC (Figure 4), it is evident that option 4 has the largest effect on both low and high efficiency ranges, in comparison to options 2 and 3. The extra power needed at the low efficiency range, translates into efficiency penalties for the cycle; however, what is more important is the combined penalty when both compressors are considered.

With regard to the HPC (Figure 5), option 2 has the largest effect on efficiency due to the HPC pressure ratio, which correlates with more power demanded from the available power delivered for compressor work. 


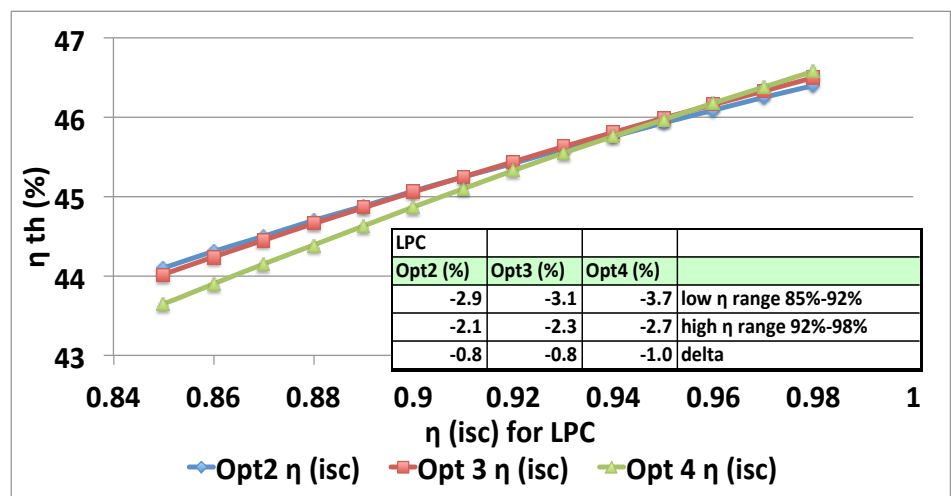

Figure 4 - Sensitivity Analysis - Effect of LPC Efficiencies on Cycle Efficiency

When both compressors are considered, option 2 (19.45\%) has the largest summation effect on efficiency observed, when compared to option 3 (18.72\%) and option 4 (19.39\%). However, for a given compressor efficiency in table 1 , option 2 yields a higher temperature rise, which means less fuel to raise the cycle temperature. As evident from Figures 4 and 5 , it is unlikely that option 2 would yield a preferred outcome, if the compressor efficiencies were less than the design point values in table 1 , hence the reason for demonstrating this effect and also to show the importance of thoroughly calculating the cycle efficiency for each OPR and the pressure ratio split per compressor, using the simulation tool.

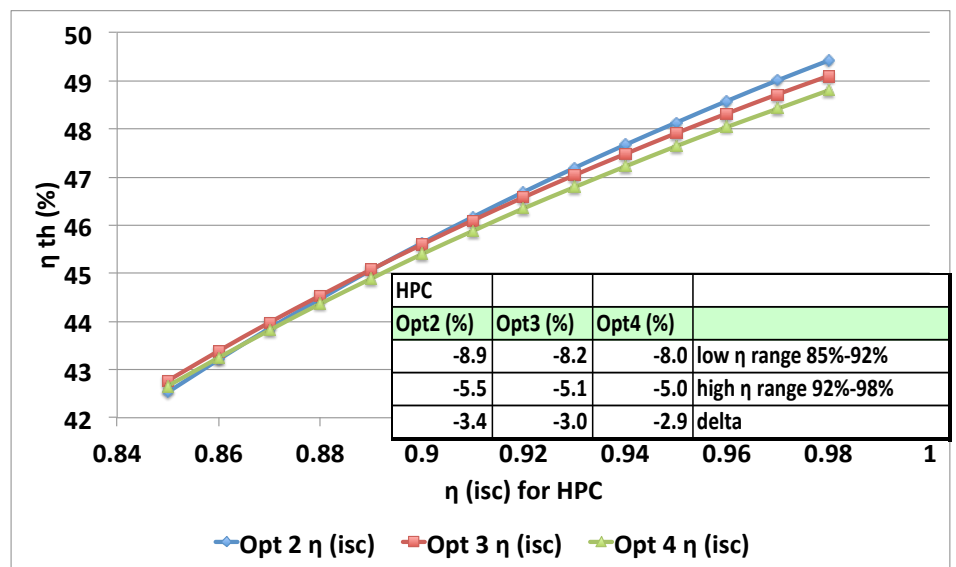

\section{Figure 5 - Sensitivity Analysis - Effect of HPC Efficiencies on Cycle Efficiency}

For the turbine (Figure 6), option 2 also has a similar trend as observed in Figure 5, with option 4 having a larger effect than option 3 . One thing that is very evident in the IC cycle is the level of importance the turbine has on cycle efficiency in comparison to the both compressors, which is more pronounced at the higher ranges; in fact if one considered the combined compressor percentage effect of $11.82 \%$ for option 2 , the turbine effect on cycle efficiency is greater than the combined compressor effect by a factor of 2.3.

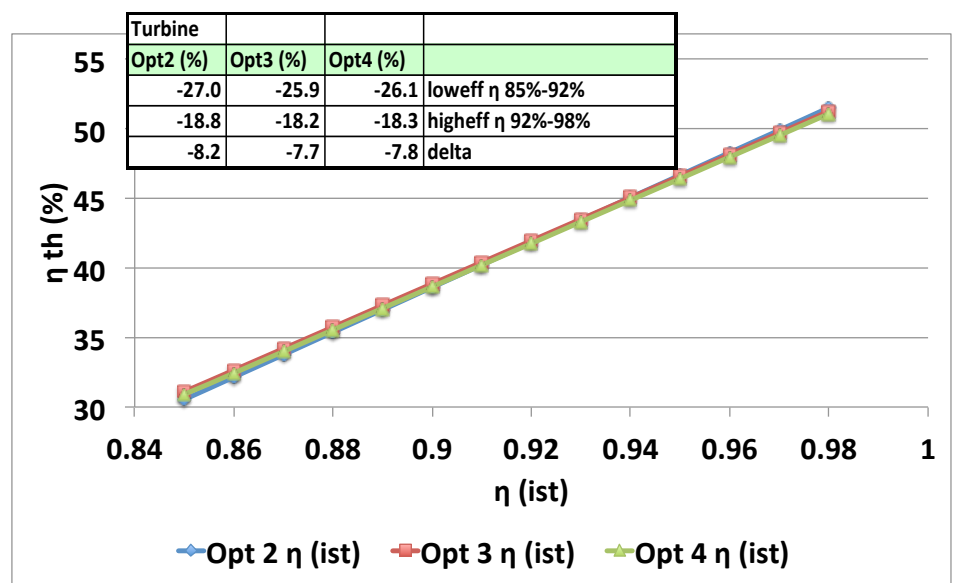

Figure 6 - Sensitivity Analysis - Effect of Turbine Efficiencies on Cycle Efficiency

From Figures 4, 5 and 6, the following summaries are drawn:

- The lower ranges of compressor and turbine efficiencies have a greater impact on the IC cycle. There are more marginal gains to increasing the HPC efficiency than the LPC but the focus of the improvements should be on a compressor with nominal efficiency $<0.89$. The other way of looking at it is that cycle efficiency is negligibly sensitive to LPC efficiency for values $0.85<\eta<0.98$. There is no need to develop the compressors beyond a certain point $(>0.92)$ because it may prove costly to compressor development to design a machine with minimal flow separation, without compromise on the stability limits.

- The cycle is more sensitive to turbine efficiency at the lower end of $0.85<\eta<0.92$, but there are still gains to be made, if turbine development programmes aimed at improving efficiencies in the range of $0.89<\eta<0.95$.

With regard to the effect of component sensitivity on specific work, the following observations are made from Figure 7, which is in line with effect on cycle efficiency:

- The turbine has the greater impact on the specific work of the plant due to the importance of extracting the power from the hot gas for the purpose of generating useful work. This process is primarily linked to the efficiency of the expansion process, where it is noted that there is a drop of $\sim 5 \%$ in specific work for every $1 \%$ drop in turbine efficiency.

- The HPC has a lesser impact on the specific work of the plant, in comparison to the turbine, where a drop of $\sim 3 \%$ for every $1 \%$ drop in HPC efficiency was noted. 
- The LPC has the least impact on specific work, where a drop of $0.9 \%$ for every $1 \%$ drop in LPC efficiency was noted.

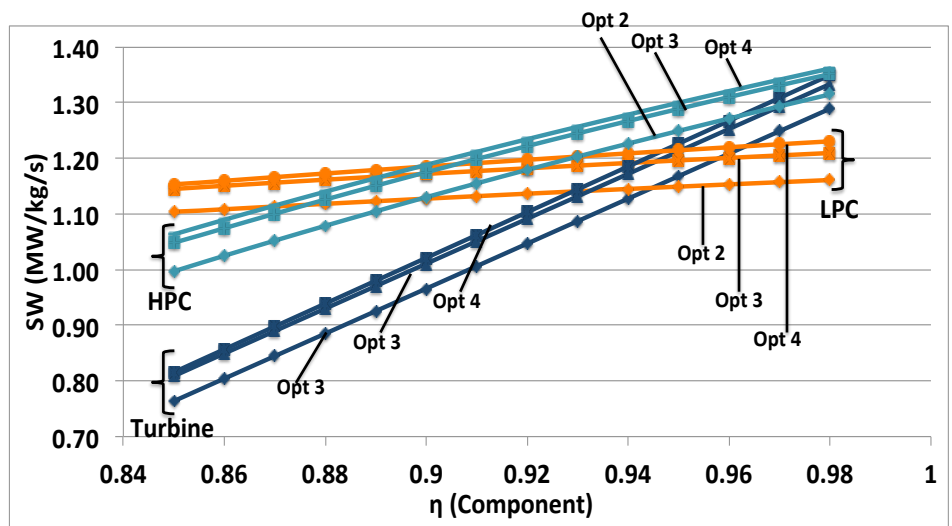

Figure 7 - Sensitivity Analysis - Effect of Component Efficiencies on Specific Work

\section{Sensitivity Analysis - Compressor Inlet Temperature}

Compressor inlet temperature is important in cycle analysis because it has an effect on the compressor work of the cycle, which affects the cycle efficiency and specific work of the plant. Nuclear plant development is sensitive to ambient conditions, especially in hot countries, where higher ambient temperature affects the cooling medium (seawater). With regard to the effect on efficiency, Figure 8 shows the trend lines for all 3 options between the range of $20-55^{\circ} \mathrm{C}$. The following observations are made:

- The work demand of the compressor is quantified by the fact that for every $1^{\circ} \mathrm{C}$ rise in temperature, there is a $0.3 \%$ increase in compressor work, which affects the useful work available.

- This equates to approximately the same amount of decrease in thermal efficiency, thus a reduction of $\sim 1.6 \%$ per $5^{\circ} \mathrm{C}$ rise.

- The increase in compressor work leads to a reduction in useful work by $\sim 18 \mathrm{MW}$. For all 3 options, the aforementioned observations old true.

- However, option 4 has the biggest impact on efficiency, with the effect pronounced at the high temperature range analysed.

- Option 3 has the least impact in comparison; in all cases the effect as previously noted shows pronounced levels of efficiency deterioration at the high temperature end.

- The same negative correlation is observed for the specific work of the cycle as noted in Figure 9 but the quantified deterioration effect on specific work is not in line with observations made in Figure 8.

- Option 2 has the biggest effect on specific work in comparison to option 4 due to reduction in useful work, but this increase is deemed to be miniscule because the effect is relatively comparable.

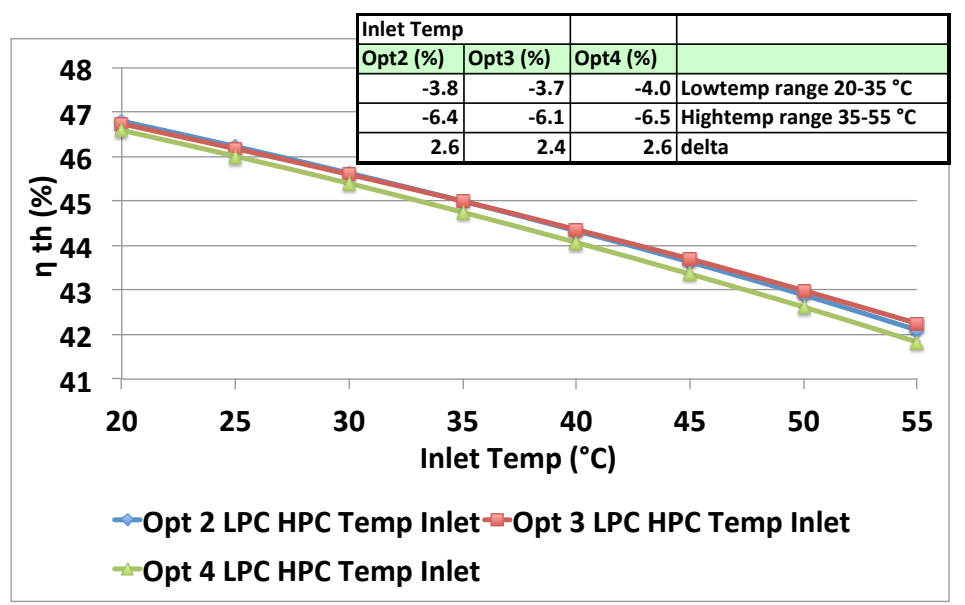

Figure 8 - Sensitivity Analysis - Effect of Compressor Inlet Temperature on Cycle Efficiency

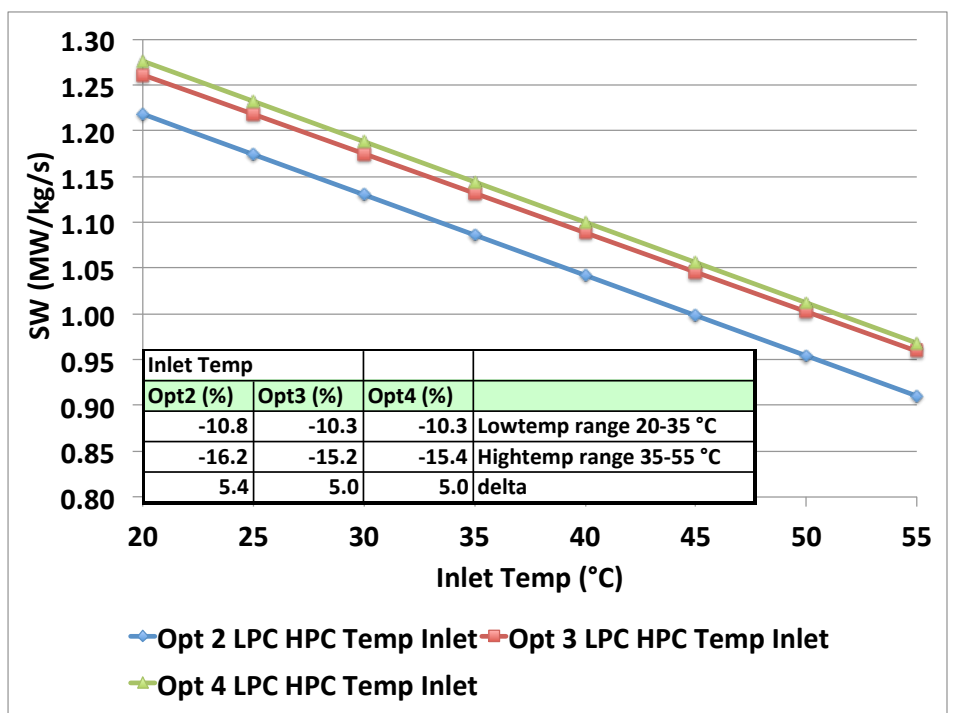

Figure 9 - Sensitivity Analysis - Effect of Compressor Inlet Temperature on Specific Work

Sensitivity Analysis - Pressure Losses

It is expected that frictional losses will be encountered, when a cycle incorporates intercooling. The reactor pressure losses also have an effect. All losses within the cycle, reduce the expansion pressure ratio relative to the compression pressure ratio, thus reducing the plant power output, due to sensitivity to irreversibilities and having a significant effect on cycle thermal efficiency. 
Table 5 quantifies the reduction in thermal efficiency experienced by the relevant components. The main thing noticeable is that option 2 pressure losses for each component has the largest effect on cycle efficiency for each component. It experiences an average total reduction in thermal efficiency of $\sim 5 \%$, when you combine each individual effect in comparison to $4.8 \%$ for option 3 and $4.6 \%$ for option 4 . The specific observations are summarised below:

- It can be observed that for each component, the effects on thermal efficiency are greater at the higher end of the range being investigated.

- However, the cycle is more sensitive to reactor and intercooler pressure losses for all the options investigated. This same trend is observed for specific work.

- The effect of the reactor and intercooler on cycle efficiency, are comparable at the higher loss range for all options.

- This suggests that nuclear plant design should minimise losses, where possible. Modularising and compacting the design in addition to reducing pipe and duct lengths help to reduce the effect.

Comparison with Simple and Intercooled Recuperated Cycles

A key measure is to assess how the IC compares to the Simple Cycle Recuperated (SCR) and Intercooled Cycle Recuperated (ICR) for the same design point values in table 1. With regard to the option of interest, option 2 offers a better solution in terms of cycle economics due to its marginally improved cycle efficiency. A similar study also conducted by the authors [9], investigated the SCR and ICR cycles with OPR of 2, used for comparison purposes with IC. The results are tabulated in tables 6 and 7 . The design point values (see table 1) are exact for all 3 cycles for the applicable components.

Table 5 - Pressure Losses Effect on Cycle Efficiency

\begin{tabular}{|r|r|r|l|}
\hline Precooler & & & \\
\hline Opt2 (\%) & Opt3 (\%) & Opt4 (\%) & \\
\hline-1.4 & -1.4 & -1.3 & low Loss Range 0-2\% \\
\hline-1.8 & -1.7 & -1.6 & high Loss Range 2-5\% \\
\hline 0.4 & 0.3 & 0.3 & delta \\
\hline MHR & & & \\
\hline Opt2 (\%) & Opt3 (\%) & Opt4 (\%) & \\
\hline-1.5 & -1.4 & -1.4 & low Loss Range 0-2\% \\
\hline-1.9 & -1.9 & -1.8 & high Loss Range 2-5\% \\
\hline 0.4 & 0.4 & 0.4 & delta \\
\hline ICHX & & & \\
\hline Opt2 (\%) & Opt3 (\%) & Opt4 (\%) & \\
\hline-1.5 & -1.4 & -1.3 & low Loss Range 0-2\% \\
\hline-1.9 & -1.8 & -1.8 & high Loss Range 2-5\% \\
\hline 0.5 & 0.4 & 0.4 & delta \\
\hline Total & & & \\
\hline Opt2 (\%) & Opt3 (\%) & Opt4 (\%) & \\
\hline-4.4 & -4.2 & -4.0 & low Loss Range 0-2\% \\
\hline-5.6 & -5.4 & -5.2 & high Loss Range 2-5\% \\
\hline-5.0 & -4.8 & -4.6 & Average \\
\hline
\end{tabular}

Table 6 - Station Output Values for all cycles (SCR, ICR \& IC)

\begin{tabular}{|c|c|c|c|c|c|c|c|c|c|c|c|c|c|c|c|c|c|c|}
\hline $\begin{array}{l}\text { St } \\
\text { No }\end{array}$ & \multicolumn{6}{|c|}{$\begin{array}{c}\text { Massflow } \\
{[\mathrm{kg} / \mathrm{s}]}\end{array}$} & \multicolumn{6}{|c|}{$\begin{array}{c}\text { Pressure } \\
\text { [MPa] }\end{array}$} & \multicolumn{6}{|c|}{$\begin{array}{c}\text { Temperature } \\
{\left[{ }^{\circ} \mathrm{C}\right]} \\
\end{array}$} \\
\hline & SCR & IC & $\Delta(\%)$ & ICR & IC & $\Delta(\%)$ & SCR & IC & $\Delta(\%)$ & ICR & IC & $\Delta(\%)$ & SCR & IC & $\Delta(\%)$ & ICR & IC & $\Delta(\%)$ \\
\hline 1 & 410.4 & 410.4 & 0.0 & 410.4 & 410.4 & 0.0 & 3.2 & 3.2 & 0.0 & 3.2 & 3.2 & 0.0 & 28 & 28 & 0.0 & 28 & 28 & 0.0 \\
\hline 2 & 405.3 & 409.4 & -0.3 & 406.3 & 409.4 & -0.7 & 6.4 & 5.5 & -85.1 & 4.5 & 5.5 & -16.8 & 135 & 107 & -71.0 & 78 & 107 & -27.4 \\
\hline $2 a$ & - & 409.4 & - & 406.3 & 409.4 & -0.7 & - & 5.3 & - & 4.5 & 5.3 & -14.7 & - & 28 & - & 28 & 28 & 0.0 \\
\hline $2 b$ & - & 406.3 & - & 406.3 & 406.3 & 0.0 & - & 43.0 & - & 6.4 & 43.0 & -85.1 & - & 464 & - & 78 & 464 & -83.3 \\
\hline 3 & 405.3 & - & - & 405.3 & - & - & 6.4 & - & - & 6.4 & - & - & 678 & - & - & 677 & - & - \\
\hline 4 & 406.3 & 406.3 & 0.0 & 406.3 & 406.3 & 0.0 & 6.2 & 42.1 & -85.2 & 6.2 & 42.1 & -85.2 & 950 & 950 & 0.0 & 950 & 950 & 0.0 \\
\hline 5 & 410.4 & - & - & 410.4 & - & - & 3.5 & - & - & 3.5 & - & - & 701 & - & - & 702 & - & - \\
\hline 6 & 410.4 & 410.4 & 0.0 & 410.4 & 410.4 & 0.0 & 3.3 & 3.3 & 0.0 & 3.3 & 3.3 & 0.0 & 164 & 210 & -21.9 & 110 & 210 & -47.6 \\
\hline
\end{tabular}


Table 7 - Cycle Results (SCR, ICR, IC)

\begin{tabular}{|c|c|c|c|c|c|c|c|c|c|c|c|c|c|c|c|c|c|}
\hline \multicolumn{6}{|c|}{$\begin{array}{c}\mathrm{CW} \\
{[\mathrm{MW}]}\end{array}$} & \multicolumn{6}{|c|}{$\begin{array}{c}\text { TW } \\
{[\mathrm{MW}]}\end{array}$} & \multicolumn{6}{|c|}{$\begin{array}{c}\text { UW } \\
\text { [MW] }\end{array}$} \\
\hline$\overline{S C R}$ & IC & $\Delta(\%)$ & ICR & IC & $\overline{\Delta(\%)}$ & \begin{tabular}{|l|}
$S C R$ \\
\end{tabular} & IC & $\Delta(\%)$ & ICR & IC & $\overline{\Delta(\%)}$ & $\overline{\text { SCR }}$ & IC & $\Delta(\%)$ & ICR & IC & $\overline{\Delta(\%)}$ \\
\hline 227 & 1096.12 & \begin{tabular}{|l|}
-79.3 \\
\end{tabular} & 211 & 1096.12 & -80.8 & \begin{tabular}{|l|}
513 \\
\end{tabular} & 1567.12 & $\begin{array}{l}-67.3 \\
\end{array}$ & 511 & 1567.12 & -67.4 & 286 & 471.00 & -39.3 & 300 & 471.00 & -36.3 \\
\hline
\end{tabular}

\begin{tabular}{|c|c|c|c|c|c|c|c|c|c|c|c|c|c|c|c|c|c|}
\hline \multicolumn{6}{|c|}{$\begin{array}{c}\text { SW } \\
{[\mathrm{MW} / \mathrm{kg} / \mathrm{s}]}\end{array}$} & \multicolumn{6}{|c|}{$\begin{array}{c}\text { Heat Input } \\
{[\mathrm{MWt}]}\end{array}$} & \multicolumn{6}{|c|}{$\begin{array}{l}n \\
\%\end{array}$} \\
\hline SCR & IC & $\Delta(\%)$ & ICR & IC & $\Delta(\%)$ & SCR & IC & $\Delta(\%)$ & ICR & IC & $\Delta(\%)$ & SCR & IC & $\Delta(\%)$ & ICR & IC & $\Delta(\%)$ \\
\hline 0.70 & 1.15 & -39.4 & 0.73 & 1.15 & -36.4 & 576 & 1026.69 & -43.9 & 580 & 1026.7 & -43.5 & 49.7 & 45.88 & 3.8 & 51.8 & 45.88 & 5.9 \\
\hline
\end{tabular}

Recuperator pressure losses for the SCR and ICR have the same design point values for their respective calculations. With reference to table 6 , it is noted that the station numbers are not aligned, especially when compared with SCR meaning only 4 stations are of interest - station numbers 1, 2, 4 and 6. For the compressor exit values, the IC value taken for comparison purposes is station number $2 \mathrm{~b}$, which is compared to station number 2 for the SCR and the delta presented in station no 2 . When compared to ICR, the situation is less complicated as both incorporate the intercooler, thus all stations are of interest with the exception of station numbers 3 and 5 .

The noticeable differences lie in the temperatures and pressures. When compared to the SCR, a $71 \%$ and $85 \%$ decrease is observed for SCR compressor exit temperature and pressure. Reactor exit pressure decrease for SCR is as per the aforementioned decrease for the compressor exit, with the turbine exit temperature showing a $22 \%$ decrease prior to recirculation. For the ICR, the observations made for pressure decreases on the SCR are comparable to that observed; the compressor exit temperature is in line with observations made for SCR but the turbine exit temperature has a bigger decrease of $48 \%$. A continued decreasing trend for the cycle parameters in table 7 is noted but there are increases in cycle efficiency of $3.8 \%$ and $5.9 \%$ for the SCR and ICR respectively.

The reality is bigger volume of helium is expected, with some upscale activities, which is required to increase volumetric capacity of the components. The draw back is the IC cycle is not competitive in comparison to SCR and ICR, if the efficiencies are taken into consideration but these cycles make use of the recuperator, which is not required for the IC, meaning the size of the plant is significantly reduced. In order to make the plant with an IC cycle more competitive, heat from the turbine exit temperature could be used in an adjacent processing plant prior to recirculation. Furthermore, the other argument for the IC is the level of pressure losses experienced on IC (5\%) is less than SCR (5.65\%) and ICR (6.6\%), due to less components, but a detailed techno-economic study will be required to evaluate the effect in terms of cycle cost. Lastly, turbine thermal capability for current turbomachinery technology is designed for TETs in excess of $950^{\circ} \mathrm{C}$. Future recuperator development to improve material thermal capability will aim to encourage higher TETs in SCR and ICR.
However, IC presents an opportunity in the immediate and near term for the cycle efficiencies to be improved by increasing the TETs beyond $950^{\circ} \mathrm{C}$. This will require further investigation of various TETs and respective optimum cycle OPRs and turbine cooling due to criticality in maintaining turbine life at elevated temperatures.

\section{Conclusion}

In summary, the objective of this investigation was to conduct a study using a performance simulation tool to analyse the Intercooled Cycle (IC) in a closed Brayton direct configuration using helium as the working fluid. The results provide a good basis to support preliminary design, testing, validation and verification activities of Gas Cooled Fast Reactors (GFR) and Very High Temperature Reactors (VHTR) for Generation IV NPPs. The main conclusions are:

- An important part of deriving the IC configuration is to derive the optimum OPR, as well as the optimum pressure ratio split. The optimum pressure ratio split is important because as demonstrated, a conventional 50:50 split between both compressors (typical split for ICR), leads to a $5 \%$ drop in efficiency from the calculated optimum efficiency of $46 \%$.

- The OPR for IC is considerably higher than typical cycles, due to the need to raise the compressor outlet temperature prior to entry into the reactor. This is evident in the 3 options with comparable efficiencies chosen for assessment, which had OPRs of 13.8, 14.04 and 14.8 .

- With regard component efficiencies, it is judged that the turbine and HPC have the greatest impact on cycle thermal efficiency and specific work. The cycle experiences an efficiency reduction of $27 \%$ for the turbine and $9 \%$ for the HPC. It is important to prioritise improvements of the turbine and HPC design to maintain higher efficiencies.

- A comparison between IC and other cycles (SCR and ICR), derived cycle efficiencies greater than IC by $\sim 4 \%$ for the SCR and $\sim 6 \%$ for the ICR respectively. The draw back is the IC cycle is not competitive in comparison to 
SCR and ICR but the size is dramatically reduced by eliminating the recuperator. Heat from the turbine exit $\left(\sim 210^{\circ} \mathrm{C}\right)$ can also be used in a processing plant to justify the business case, including the lower pressure losses in comparison to SCR and ICR; a technoeconomic study will be required to evaluate all effects in terms of cycle costs.

- Due to current turbine material capability, the opportunity exists to investigate TETs beyond $950^{\circ} \mathrm{C}$ in the immediate and near term. Cooling is a necessity, especially if higher TETs are to be investigated. The most optimum cooling amount to minimise thermal stresses, versus cost of a better material, requires investigating to understand the relationship of fuel costs versus maintaining efficiency, and cooling optimisation versus improved material selection.

\section{Acknowledgements}

The authors wish to thank the Gas Turbine Engineering Group at Cranfield University for providing the necessary support in progressing this research study.

\section{References}

[1] G. Locatelli, M. Mancini, and N. Todeschini, "Generation IV nuclear reactors: Current status and future prospects," Energy Policy, vol. 61, pp. 1503-1520, Oct. 2013.

[2] Nuclear Research Advisory Committee and Generation IV International Forum, "A Technology Roadmap for Generation IV Nuclear Energy Systems," Report No: GIF-002-00, US DOE, Washington D.C., USA, 2002.

[3] R. K. Bhargava, M. Bianchi, A. De Pascale, G. N. Montenegro, and A. Peretto, "Gas Turbine Based Power Cycles - A State-of-the-Art Review," International Conference on Power Engineering, April 12-14, Setubal, Portugal, 2007.

[4] H. I. H. Saravanamuttoo, G. F. C. Rogers, H. Cohen, and P. V Straznicky, Gas Turbine Theory, 6th ed. England: Pearson Education Limited, 2009.

[5] K. N. Pradeepkumar, A. Tourlidakis, and P. Pilidis, "Analysis of $115 \mathrm{MW}$, 3-Shaft, Helium Brayton Cycle using Nuclear Heat Source," in Proceedings of ASME Turbo Expo 2001 Land, Sea \& Air. June 4-7, 2001., IGTI, Louisiana, New Orleans, USA, 2001.

[6] K. N. Pradeepkumar, A. Tourlidakis, and P. Pilidis, "Design and Performance review of PBMR Closed Cycle Gas Turbine Plant in South Africa.,"ASME International
Joint Power Generation Conference. June 4-7 2001, Louisiana, New Orleans, USA, 2001.

[7] K. N. Pradeepkumar, A. Tourlidakis, and P. Pilidis, "Performance Review: PBMR Closed Cycle Gas Turbine Power Plant.," in Proceedings of Technical Committee Meeting on HTGR - Power Conversion Systems. International Atomic Energy Agency. 14-16 November 2000, Paulo Alto, USA, 2001, pp. 99-112.

[8] H. Sato, X. L. Yan, Y. Tachibana, and K. Kunitomi, "GTHTR300-A nuclear power plant design with 50\% generating efficiency," Nucl. Eng. Des., vol. 275, pp. 190196, Aug. 2014.

[9] A. Gad-Briggs and P. Pilidis, "Analyses of Simple and Intercooled Recuperated Direct Brayton Helium Gas Turbine Cycles for Generation IV Reactor Power Plants," J. Nucl. Eng. Radiat. Sci., DOI: 10.1115/1.4033398, 2016. 
2016-12-20

\section{Analyses of a high pressure ratio intercooled direct Brayton helium gas turbine cycle for Generation IV reactor power plants}

Gad-Briggs, Arnold

ASME

A. Gad-Briggs, P. Pilidis and T. Nikolaidis, Analyses of a high pressure ratio intercooled direct Brayton helium gas turbine cycle for Generation IV reactor power plants, Journal of Nuclear Engineering and Radiation Science, Volume 3, Issue 1, 2016, 011021

http://dx.doi.org/10.1115/1.4034479

Downloaded from Cranfield Library Services E-Repository 